\title{
A Non-Destructive Technique for Health Assessment of Fire-Damaged Concrete Elements Using Terrestrial Laser Scanning
}

\author{
Wallace Mukupa*, Gethin W. Roberts, Craig M. Hancock, Khalil Al-Manasir \\ Department of Civil Engineering, The University of Nottingham Ningbo, China \\ 199 Taikang East Road, University Park, Ningbo 315100, China. \\ *Corresponding Author.Email: wallace.mukupa@nottingham.edu.cn,wallacemukupa@yahoo.com
}

\begin{abstract}
Concrete structures are routinely monitored to detect changes in their characteristics in the field of engineering surveying and other disciplines such as structural and civil engineering. There is growing demand for the development of reliable Non-Destructive Testing (NDT) techniques for concrete structures in the assessment of the deteriorating condition of infrastructures or in an event of fire-damaged structures. In this paper, the feasibility of using Terrestrial Laser Scanning (TLS) technology for change detection and assessment of fire-damaged concrete has been investigated through measurements and analysis of laboratory size concrete specimens that underwent heating up to $1000^{\circ} \mathrm{C}$. The TLS technique employed in detecting fire-damaged concrete involved modelling and analysis of the TLS intensity returns as well as RGB image analysis. The results obtained clearly demonstrate the feasibility of using TLS to detect firedamaged concrete. Although the laser scanners used in the study have different wavelengths, the results obtained in both cases are promising for a detection technique of fire-damaged concrete structures.
\end{abstract}

Key words: Terrestrial Laser Scanning, Fire-Damaged Concrete, Assessment, Change Detection

\section{Introduction}

Concrete is the most extensively used construction material worldwide with an average global yearly consumption of $1 \mathrm{~m}^{3}$ per person $[1,2]$ and many engineering structures are made of concrete. Fire is one of the most serious potential risks to many buildings and structures. Most research work that has been carried out addressing the effects of fire-damaged concrete has been motivated by the extensive use of concrete as a construction material [3] around the world. According to Ergün et al. [4] one of most damaging environmental effects for concrete structures is exposure to elevated temperatures and concrete structures such as bridges, viaducts, tunnels, buildings and parking garages are examples of structures at risk of fire damage [5]. Even though concrete is known to be a material with high fire resistance and capable of retaining much of its load-bearing capacity, it undergoes severe modifications in its physical, chemical and mechanical properties when subjected to high temperatures [6].

The first and most cardinal task for structural safety appraisal of a concrete structure that has been subjected to fire is damage assessment [6]. A damage assessment in such a case aims at providing the relevant information needed to evaluate the residual bearing capacity and durability of the fire-damaged structure and to propose appropriate repair methods or to decide if demolition is more appropriate [7]. A thorough assessment of a fire-damaged structure consists of a combination of field and laboratory investigations which are explained in detail below. These investigations are carried out so as to determine the extent of fire damage and in order to devise proper and cost effective repair measures. In particular, Gosin et al. [8] state that the assessment process should quantify the magnitude and degree of damage to structural elements since this will determine the repair costs. The primary field (on-site) investigation method is visual inspection, which records features such as collapse, distortion, deflections, degree of damage to materials and smoke damage. A tapping survey of element surfaces may 
be conducted. Simple invasive investigation techniques such as using a hammer and chisel may also be used. In terms of laboratory (off-site) investigations, samples of damaged material and undamaged references may also be removed for laboratory testing and examinations [5]. These tests would for instance include: core strength, ultrasonic pulse velocity, Windsor probe, BRE internal fracture and petrographic examinations [9]. Table 1 below shows a summary of the existing methods for the assessment of fire-damaged structures. Normally, a damage classification chart for the elements involved in a fire is prepared as an output from the assessment process and such a chart can be used in the selection of appropriate repair techniques $[8,10]$.

Table 1: Methods for assessment of fire-damaged structures

\begin{tabular}{|c|c|c|c|c|}
\hline \multirow{2}{*}{ Test Location } & \multirow{2}{*}{ Test Type } & \multirow{2}{*}{ Test Method } & \multicolumn{2}{|c|}{ Structural Material } \\
\hline & & & Concrete & Masonry \\
\hline \multirow[t]{6}{*}{ On-site } & \multirow{5}{*}{$\begin{array}{l}\text { Non } \\
\text { destructive }\end{array}$} & Visual Inspection & $\checkmark$ & $\checkmark$ \\
\hline & & Endoscope survey & & $\checkmark$ \\
\hline & & Hammer soundings & $\checkmark$ & $\checkmark$ \\
\hline & & Rebound hammer & $\checkmark$ & $\checkmark$ \\
\hline & & Ultrasonic testing & $\checkmark$ & $\checkmark$ \\
\hline & \multirow{4}{*}{$\begin{array}{l}\text { Partially } \\
\text { destructive }\end{array}$} & Breakout / drilling & $\checkmark$ & $\checkmark$ \\
\hline \multirow[t]{3}{*}{ Laboratory } & & Load test & $\checkmark$ & $\checkmark$ \\
\hline & & $\begin{array}{l}\text { Petrographic } \\
\text { examination }\end{array}$ & $\checkmark$ & $\checkmark$ \\
\hline & & Compressive strength & $\checkmark$ & $\checkmark$ \\
\hline
\end{tabular}

Source: Ingham [5] and Short et al. [9].

Within the field of civil engineering, various studies have been conducted aimed at investigating the effects of heating rate, elevated temperature exposure and the exposure duration on the residual strength of concrete $[6,11,12]$. It has been reported that when concrete is heated between $200^{\circ} \mathrm{C}$ and $250^{\circ} \mathrm{C}$ it begins to undergo loss in its compressive strength. Furthermore, the compressive strength of concrete at temperatures between $300^{\circ} \mathrm{C}$ and $500^{\circ} \mathrm{C}$ is reduced to about 15 to $70 \%$ of that of unheated concrete [4]. The temperature of $300^{\circ} \mathrm{C}$ is commonly taken to be the benchmark temperature above which concrete is considered to have been significantly damaged [13]. Several techniques that assess fire-damaged concrete have been presented as mentioned above and colour change is also one of them as investigated by several researchers and results have shown that concrete containing siliceous aggregate when heated at elevated temperatures undergoes colour changes from normal to pink/red at temperatures between $300^{\circ} \mathrm{C}$ and $600^{\circ} \mathrm{C}$ to whitish grey/black round $600^{\circ} \mathrm{C}$ to $900^{\circ} \mathrm{C}$ and buff at $900^{\circ} \mathrm{C}$ to $1000^{\circ} \mathrm{C}$ [14-16].

In this study, Terrestrial Laser Scanning (TLS) was investigated for detection of fire-damaged concrete and with the motivation based on the following: with laser scanning the whole concrete element can be scanned and an average intensity value over the area concerned can be determined which would represent the whole element overcoming the challenge of cores drilled in limited areas for some conventional techniques; scanning is quick with millions of points measured in a few seconds and this is advantageous for engineering structures considering their scale or magnitude; scanning of a fire-damaged structure can be done from a distance which improves safety; and laser scanning is a non-destructive technique for detecting fire-damaged concrete. Laser scanner intensity values have been used in different applications and one of the prominent one is change detection and classification of different material [17-19]. This evidence for detecting and classifying various materials based on the laser scanner intensity values has necessitated an investigation into the idea of using the TLS intensity values to collect data about unheated and heated concrete and interpret that data with regard to the condition of the concrete as a non-destructive technique for detecting and assessing firedamaged concrete. 
The addition of intensity data to the geometric data has proved useful in several applications $[19,26,27]$ and a study by Teza et al. [20] showed a successful method based on curvature analysis of TLS geometric data and aimed at recognizing surface defects of a concrete bridge due to mass loss. However, laser scanner intensity data is not often utilised, because it is affected by several factors such as scanning distance and incidence angle, water content, ambient light, humidity, type of laser and object surface properties [21, 22]. Therefore, according to the authors of this paper in a preliminary study of detecting fire-damaged concrete using laser scanning, it is stated that the ability to effectively identify concrete that has been heated to certain temperatures implies modelling these factors that have an influence on returned intensity [23]. In this study the influencing factors on intensity were incidence angle and distance as the experiments were carried out in a controlled environment and the concrete was dry.

An overview review of existing assessment methods of fire-damaged concrete has been presented above and this paper focuses on investigating the use of laser scanning intensity to detect fire-damaged concrete as a non-destructive technique. The experimental design and testing procedure for the proposed laser scanning technique and a colourimetry approach to detecting fire-damaged concrete are explained in detail. The results of the proposed technique are presented to demonstrate its feasibility and validity.

\section{Experimental Design and Testing Procedure}

\subsection{Materials and Experimental Specimens}

Ordinary materials were used to make concrete specimens and these included: cement, water, sand and aggregate. The cement used was Composite Portland (P.C32.5). Natural siliceous river sand with a maximum grain size of $5 \mathrm{~mm}$ was used as a fine aggregate whereas crushed siliceous aggregate with diameter ranging from 5 to $20 \mathrm{~mm}$ was the coarse aggregate. Ordinary normal strength concrete specimens of prism type with dimensions $400 \times 100 \times 100 \mathrm{~mm}$ were prepared. The mix proportion and the properties are given in Table 2.

Table 2: Material and Properties of Concrete Specimens

\begin{tabular}{|l|l|}
\hline Material & $\begin{array}{l}\text { Water, Sand, Aggregate and Composite } \\
\text { Portland Cement }\end{array}$ \\
\hline Mix Proportions & $\begin{array}{l}0.44: 1: 1.42: 3.17 \\
\text { (Water/cement/sand/aggregate) }\end{array}$ \\
\hline Water-Cement ratio & 0.44 \\
\hline Curing Period & 28days \\
\hline
\end{tabular}

The concrete specimens were cast in steel moulds (Fig. 1) and consolidated using a high frequency vibrating table. After 24 hours of casting, the specimens were removed from the moulds and then cured in a fresh water tank where the temperature and humidity were kept at $20 \pm 2^{\circ} \mathrm{C}$ and $40 \%$ respectively for 28 days.

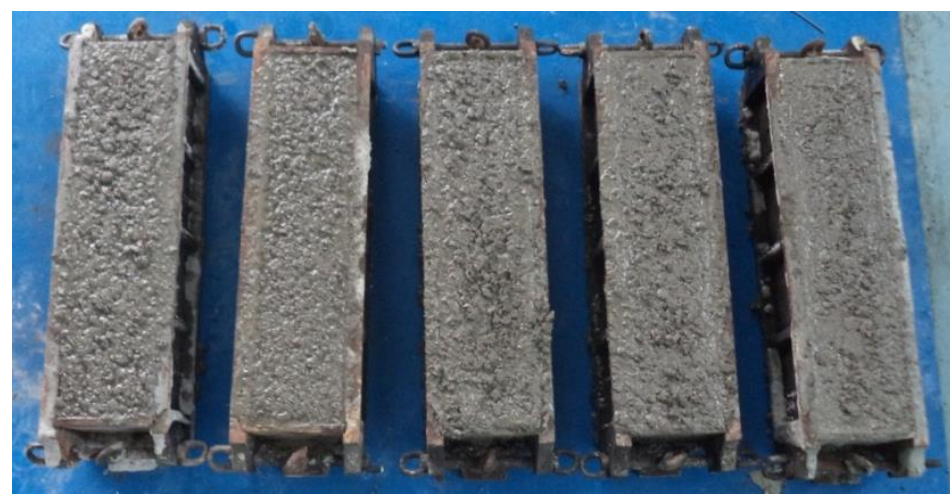

Fig. 1: Concrete specimens cast in steel moulds 


\subsection{Scanning Room and Equipment Specifications}

In order to isolate and focus only on the scanning geometry (incidence angle and distance) as the influencing factors for poor return signal i.e. TLS intensity, the experiment was conducted in a controlled environment. Table 3 shows the technical specifications of two phase shift terrestrial laser scanners (Leica HDS 7000 and FARO Focus ${ }^{3 D} 120$ ) that were used to scan the specimens before and after heating. The DT-8820 digital multifunction environment meter was used to measure temperature and relative humidity in the room where experiments were conducted. The measured temperature was $14^{\circ} \mathrm{C}$ whereas the relative humidity was $42 \%$.

Table 3: Specification of TLS Instruments

\begin{tabular}{|l|l|l|}
\hline Instrument & Leica HDS7000 & FARO Focus ${ }^{\mathbf{3 D}} \mathbf{1 2 0}$ \\
\hline Ranging method & Phase & Phase \\
\hline Wavelength & $1500 \mathrm{~nm}$ & $905 \mathrm{~nm}$ \\
\hline Field of View (Ver/Hor) & $320^{\circ} \times 360^{\circ}$ & $300^{\circ} \times 360^{\circ}$ \\
\hline Laser Class & 1 & $3 \mathrm{R}$ \\
\hline Range & $0.3-187 \mathrm{~m}$ & $0.6-120 \mathrm{~m}$ \\
\hline Samples/sec & 1016000 & 976000 \\
\hline Beam diameter & $\sim 3.5 \mathrm{~mm} @ 0.1 \mathrm{~m}$ & Typical 3mm @ exit, circular \\
\hline Beam divergence & $<0.3 \mathrm{mrad}$ & Typical $0.19 \mathrm{mrad}$ \\
\hline Colour & external & integrated \\
\hline Temp Range & $0-45^{\circ} \mathrm{C}$ & $5-40^{\circ} \mathrm{C}$ \\
\hline
\end{tabular}

Source: Leica Geosystems [24] and FARO Technologies [25].

\subsection{Experiment Setup and Concrete Scanning}

The planned distances for investigation between the scanner and concrete blocks were 1, 2, 3, 4, 5 and 6 metres and the total station (TS 11) was used in the measurement setup and in particular marking out the scanning distances. The geometry of the experiment in terms of scanning measurement setup is shown in Fig. 2.

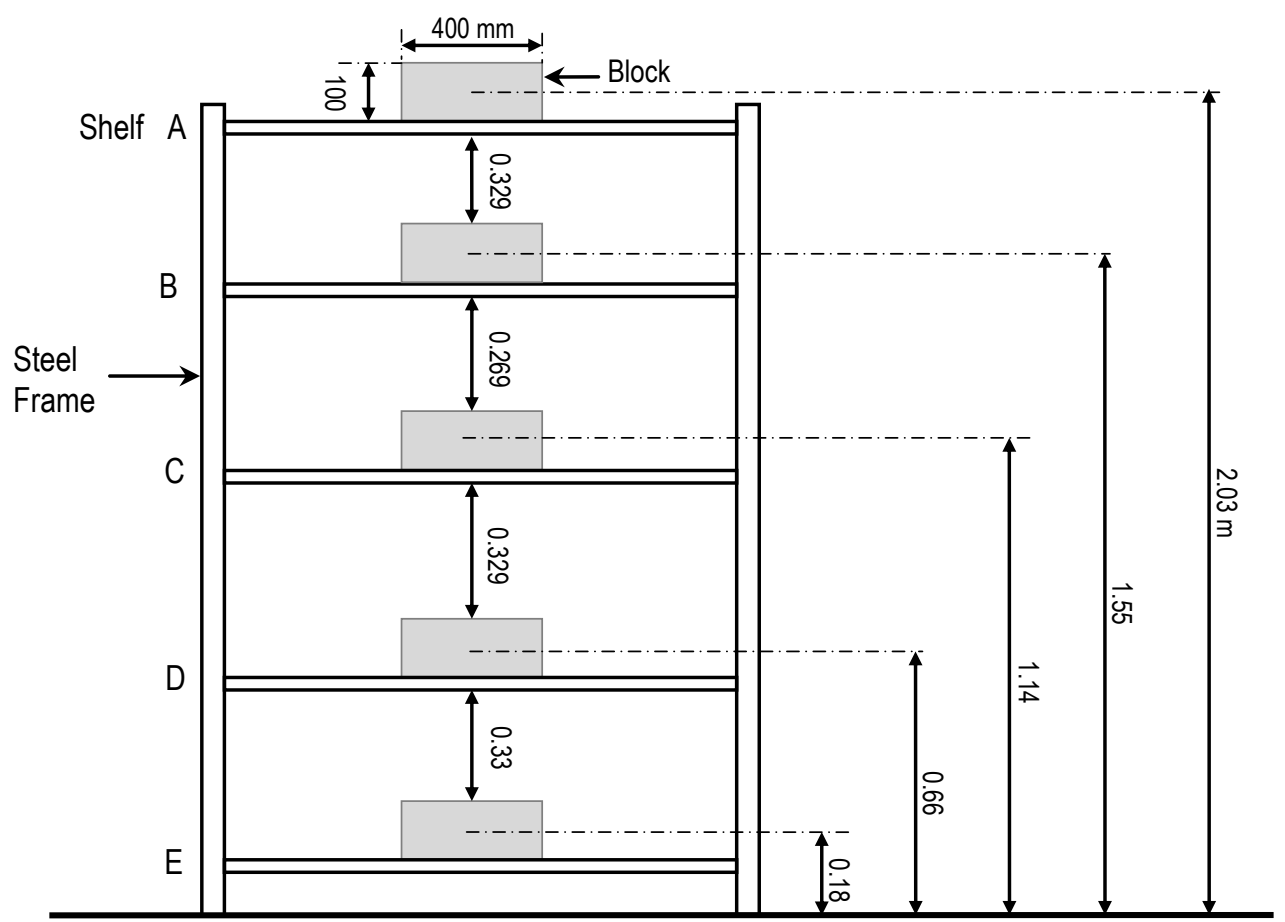

Fig. 2: Steel Frame and Blocks at Different Levels. The letters A, B, C, D and E stand for shelves.

With reference to Fig. 2, the planar surface of each concrete block was properly aligned with the frame edge. The concrete blocks were placed at different heights on shelves of the steel 
frame with the control block on the centre shelf at the same height as the scanner with its front face approximately vertical and perpendicular to ensure that scanning was done at roughly normal angle of incidence. The experiment was set-up this way in order to only focus on the scanning geometry as the factor influencing the poor laser returned signal. The scanning parameters used in the experiments are shown in Table 4 and involved a comparative analysis of scanning resolutions for the two scanners used as compiled from the user manuals courtesy of Leica Geosystems and FARO Technologies.

Table 4: Scanning Parameters

\begin{tabular}{||l|l||}
\hline \multicolumn{1}{||}{ Leica HDS7000 Scanner } & \multicolumn{1}{c||}{ FARO Focus 120 Scanner } \\
\hline Middle resolution: $12.6 \mathrm{~mm} / 10 \mathrm{~m}$ & $1 / 8$ resolution, Quality $4 \mathrm{X}: 12.272 \mathrm{~mm} / 10 \mathrm{~m}$ \\
\hline High resolution: $6.3 \mathrm{~mm} / 10 \mathrm{~m}$ & $1 / 4$ resolution, Quality $4 X: 6.136 \mathrm{~mm} / 10 \mathrm{~m}$ \\
\hline Super high resolution: $3.1 \mathrm{~mm} / 10 \mathrm{~m}$ & $1 / 2$ resolution, Quality $4 \mathrm{X}: 3.068 \mathrm{~mm} / 10 \mathrm{~m}$ \\
\hline
\end{tabular}

Source: Leica Geosystems [24] and FARO Technologies [25].

Fig. 3a and $3 \mathrm{~b}$ below show the experiment setup when the HDS7000 and the FARO scanners were used to scan the concrete specimens. The whole essence of using two types of scanners was to investigate the behaviour of two different scanners and investigate their relationships since the two scanners that were used have different wavelengths for instance.



Fig. 3a: Scanning using the HDS7000 scanner

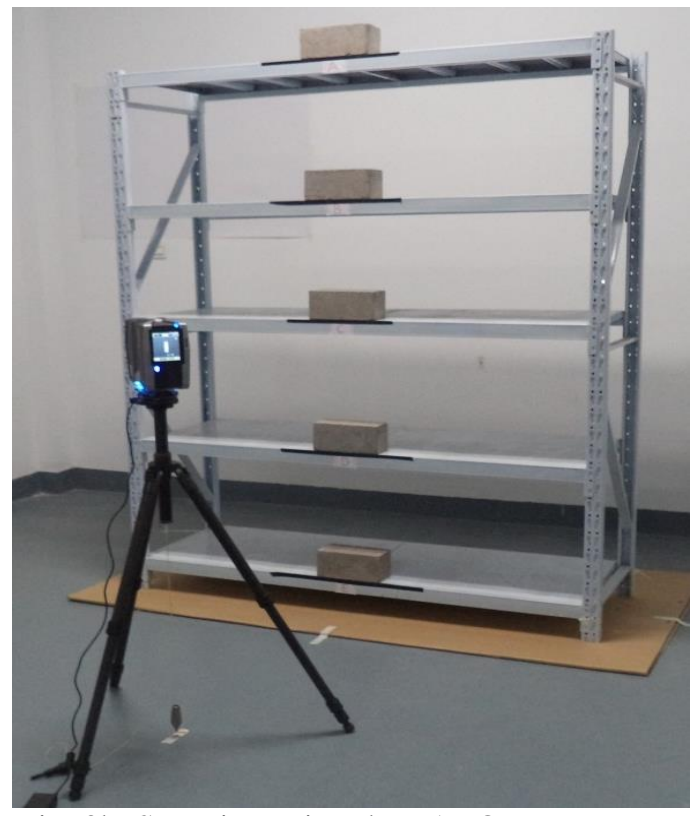

Fig. 3b: Scanning using the FARO scanner

\subsection{Heating Exposure Technique}

After scanning the unheated concrete specimens with the two laser scanners, the specimens had to then be heated. A Carbolite CWF 12/23 electric furnace was used for the thermal treatment of the specimens. The specimens at an age of 98 days were placed in the furnace chamber and thereafter heated at designated temperatures of $250,400,700$, and $1000^{\circ} \mathrm{C}$ with a ramping rate of $10^{\circ} \mathrm{C} / \mathrm{min}$. For each heated specimen, thermal cycles were followed as depicted in (Fig. 4) for the specimen that was heated to $1000^{\circ} \mathrm{C}$ because rapid heating rate can also result in higher vapour pressure and cause cracks in concrete [4]. The peak temperatures were maintained for 1 hour and then after an exact period of 1 hour, the furnace was switched off with the specimen inside and left to cool down to room temperature in order to avoid thermal shock. For comparison purpose with the other heated specimens, one specimen was left unheated. 




Fig. 4: Thermal cycle for the concrete block heated to $1000^{\circ} \mathrm{C}$

The concrete specimens were then scanned immediately after cooling the same way as prior to heating since heated concrete undergoes the re-hydration processes [28].

\section{Scan Data Pre-processing}

The FARO Scene proprietary data processing software was used to batch convert and export the FARO scans (.fls) files to text files (.pts) format, which is an ASCII format, simple text file and can be edited by many programs as the files are adapted to move freely between multiple software packages. The exported text files contained 3D points and the intensity value for each of the points since the result of a scan involves a point cloud with several observations $\left[x_{i}, y_{i}, z_{i}\right]_{i \ldots . . . n}$ consisting of 3D positions of the points in a Cartesian coordinate system and the intensity. Since the scanned data were exported to .pts format, the intensity values were ranging from -2047 to +2048 . The HDS7000 scans (.zfs) were also converted to text files (.pts) using the batch conversion function of zfs files in $\mathrm{Z}+\mathrm{F}$ laser control software. The alignment and rotation of data was performed using developed Matlab scripts applying the polyfit and polyval functions and where the rotation matrix R, (Eq. 1) was implemented.

$$
\mathrm{R}=\left[\begin{array}{cc}
\cos \theta & -\sin \theta \\
\cos \theta & \sin \theta
\end{array}\right]
$$

After the alignment stage each scan dataset was limited by the distance at which it was scanned and then written to a new file using Matlab functions. The preceding steps were helpful in devising a proper way of selecting and clipping the blocks from the point cloud. The points that belonged to the blocks were selected from the resulting point cloud of each scan using Matlab scripts. Based on the Cartesian coordinates, the horizontal angle $\theta$, vertical angle $\phi$ and the range, $p$ from the scanner to the target object were calculated using Eq. (2) [29, 30].

$$
\left[\begin{array}{c}
p_{i} \\
\theta_{i} \\
\phi_{i}
\end{array}\right]_{i=1 \ldots n}=\left[\begin{array}{c}
\sqrt{x_{i}^{2}+y_{i}^{2}+z_{i}^{2}} \\
\tan ^{-1}\left(\frac{y_{i}}{x_{i}}\right) \\
\tan ^{-1}\left(\frac{z_{i}}{\sqrt{x_{i}^{2}+y_{i}^{2}}}\right)
\end{array}\right]_{i=1 \ldots . . n}
$$


Incidence angles can be computed by determining the normal of a point with the aid of points around its neighbourhood. However, since the measurement setup in terms of the scanning geometry was optimised, it was discovered that the incidence angle at the centre of each block was the same as the scanning vertical angle. Statistics for each block such as intensity means and standard deviations were also calculated. It is worth mentioning that intensity values are dimensionless and that the mean intensity value for the area selected around each block was used for the analysis.

\section{Intensity Data Correction}

The intensity correction method by Fang et al. [31] based on the laser transmission function and the radar (range) equation was adopted and applied in this study to correct concrete intensity data acquired using the HDS7000 laser scanner for near distance effects. An overview of the intensity correction is presented and detailed information can be found in Fang et al. [31]. First and foremost, the simplified radar (range) equation (Eq. (3)) can be written as:

$$
P_{r}=\frac{P_{t} D_{r}^{2} p}{4 R^{2}} \eta_{s y s} \eta_{a t m} \cos \alpha
$$

Where $P_{r}$ is the received power, $P_{t}$ is the power transmitted, $D_{r}$ is the receiver aperture, $p$ is the reflectance of the object, $R$ is the range, $\alpha$ is the incidence angle, $\eta_{\text {sys }}$ and $\eta_{\text {atm }}$ are system and atmospheric factors respectively $[17,32]$.

Under the assumption of the target object with Lambertian scattering properties and covering the entire hemisphere implies a solid angle of $\pi$ steradian and so the effective aperture $D_{r}^{2}=4$ is equivalent to $\pi$. With these assumptions considered, Eq. (3) can be rewritten as described in Eq. (4) [22]:

$$
P_{r}=\frac{P_{t} \cos \alpha}{R^{2}} \pi p \eta_{\text {sys }} \eta_{a t m}
$$

For close-range terrestrial laser scanners Eq. (4) can be written as:

$$
P_{r}=\frac{C_{E} p \cos \alpha}{R^{2}}
$$

Where the term $\mathrm{C}_{\mathrm{E}}=\left(P_{t} D_{r}^{2} / 4\right) \eta_{\text {Sys }} \eta_{\text {Atm }}$ in Eq. (3) is taken to be a constant. $\mathrm{P}_{\mathrm{r}}$ (power received) is taken to be equivalent to the recorded laser returned intensity [31]. Eq. (5) is a suitable physical based model under the assumptions mentioned above. However, in reality different relations have been observed between intensity and range for TLS than described by the physical model at near distances due to factors such as instrumental effects [27, 33, 26, 31] causing the physical model to be inapplicable at all scanning distances. Theoretically, the effects of the range and the angle of incidence on the intensity have been found to be independent, implying that it is possible to solve each one of them separately. In the analysis of the near-distance effects, Fang et al. [31] state that for a coaxial laser scanner, the near-distance effect can be described as the ratio of the input laser signal that the detector captures between the limited range (R) and unlimited range $(\infty)$ as shown in Eq. (6):

$$
\eta(R)=\frac{P(R)}{\mathrm{p}(\infty)}=1-\exp \left\{\frac{-2 r_{d}^{2}(R+d)^{2}}{D^{2}\left[\left(1-\frac{s_{d}}{f}\right) R+d-\frac{d s_{d}}{f}+s_{d}\right]^{2}}\right\}
$$

Where $r_{d}$ is the radius of the circular laser detector, $d$ is the offset between the measured range $\mathrm{R}$ and the object distance from the lens plane, $\mathrm{D}$ is the diameter of the lens, $\mathrm{S}_{\mathrm{d}}$ is the fixed distance of the detector from the lens and $\mathrm{f}$ is the focal length. All of which are parameters of 
the laser scanner. Combining Eq. (6) with Eq. (5) and taking into account the near-distance effect, the intensity value can be written as:

$$
I(R, \alpha, p) \propto P(R, \alpha, p)=\eta(R) \frac{C_{E} p \cos \alpha}{R^{2}}
$$

In a case of constant reflectance of a target and with an incidence angle of $0^{\circ}$, then the term $y=$ $\mathrm{C}_{\mathrm{E}} \mathrm{p} \cos \alpha$ is regarded a constant and the relation between intensity and range can be written as [31]:

$$
F(R)=\frac{y}{\mathrm{R}^{2}}=\left\{1-\exp \left\{\frac{-2 r_{d}^{2}(R+d)^{2}}{D^{2}\left[\left(1-\frac{s_{d}}{f}\right) R+d-\frac{d s_{d}}{f}+s_{d}\right]^{2}}\right\}\right\}
$$

In their study, Fang et al. [31] used a Z+F Imager 5006i laser scanner and it has been reported that the parameters in Eq. (8) have a physical basis and that these parameters as shown in Table 5 were estimated in accordance with observed values such as the receiver's diameter and the detector's distance from the lens plane by iterative curve fitting using a nonlinear least squares method and robust Gauss-Newton algorithm.

Table 5: Values of Estimated Parameters

\begin{tabular}{c|cccccc}
\hline Parameters & $\boldsymbol{y}(\boldsymbol{i n c})$ & $\boldsymbol{r}_{\boldsymbol{d}}(\boldsymbol{m})$ & $\boldsymbol{d}(\boldsymbol{m})$ & $\boldsymbol{D}(\boldsymbol{m})$ & $\boldsymbol{s}_{\boldsymbol{d}}(\boldsymbol{m})$ & $\boldsymbol{f}(\boldsymbol{m})$ \\
\hline Lower & 0.0 & 0.0 & -1.0 & 0.03 & 0.01 & 0.05 \\
Upper & Inf & 0.005 & 0.2 & 0.6 & 0.9 & 0.5 \\
Initials & $3 \mathrm{e}+8$ & $1 \mathrm{e}-3$ & -0.18 & 0.05 & 0.18 & 0.15 \\
Optimized & $4.678 \mathrm{e}+8$ & $2.5 \mathrm{e}-3$ & -0.7538 & 0.05035 & 0.1608 & 0.1704 \\
\hline
\end{tabular}

Source: Fang et al. [31].

The concrete intensity data from the FARO scanner showed insignificant near distance effects and no correction was applied. For both scanners used, the data analysed for incidence angles were below $12^{\circ}$ and concrete was fairly smooth. Though the estimated parameters in Table 5 were obtained using the $\mathrm{Z}+\mathrm{F}$ Imager 5006i laser scanner, the procedure and parameters were tested for the HDS7000 laser scanner since the two instruments are coaxial and basically the same in terms of their physical characteristics as designed by the manufacturer. The concrete intensity data acquired using the HDS7000 scanner could be corrected for all other distances with the exception of the $1 \mathrm{~m}$ distance (see Fig. 13).

\section{Colourimetry Approach}

The approach to assessing colour change of heated concrete as explained in detail below was twofold. Firstly, a flatbed scanner was employed to scan the heated concrete samples. The concrete image capture procedure employed is similar to that of Hager [15]. After heating and cooling the concrete, images were captured from the specimen surfaces using a flatbed scanner (HP Scanjet G2410). Images of concrete specimens were taken using the scanner at a resolution of 600ppi and saved as TIF files. Sizeable images were then cropped for analysis. The images were normalised for effects of intensity using Matlab scripts. The normalised images were then analysed using ImageJ software. The image processing procedure involved splitting the RBG image into individual channels and analysing the channels in terms of their intensities of the normalised maximum values [15] so as to draw some statistical trends. Secondly, an attempt was also made to capture concrete pictures using the M-Cam attached to the Leica HDS7000 laser scanner but the images obtained were not of good resolution and were not used in data processing and analysis. 


\section{RESULTS AND ANALYSIS}

\subsection{Colour Change of Heated Concrete}

Visual inspection of colour change is for instance one of the initial steps in assessment of firedamaged concrete [12] which may then be followed by detailed investigations [9]. Visual inspection of colour change of heated gives an idea of the modification in the properties of concrete [28] and shown in Fig. 5 are the concrete specimens and their respective colour change after heating.

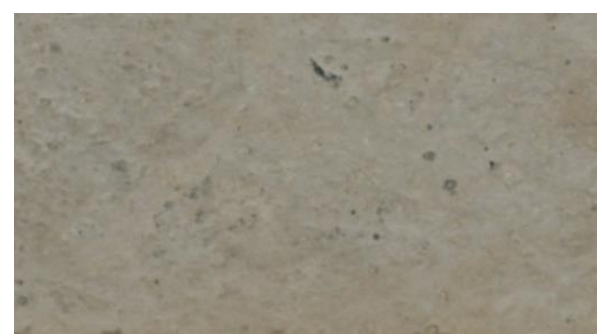

(a) Concrete block heated at $250^{\circ} \mathrm{C}$

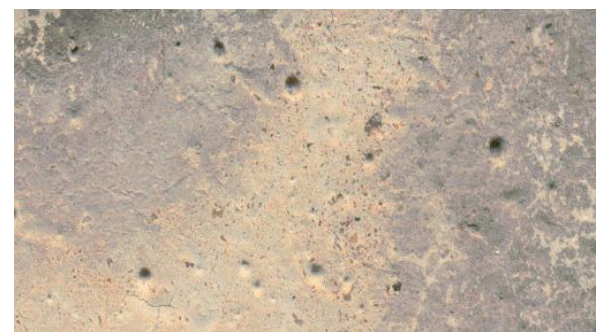

(c) Concrete block heated at $700^{\circ} \mathrm{C}$



(b) Concrete block heated at $400^{\circ} \mathrm{C}$



(d) Concrete block heated at $1000^{\circ} \mathrm{C}$

Fig. 5: Colour Change of Heated Concrete.

The concrete colour changes in Fig. 5 generally show the same widely reported colours of concrete containing siliceous aggregate when it is heated to high temperatures as mentioned above. Importantly, colour changes as observed in Fig. 5 can be useful in identifying the extents of fire-damaged concrete [5] and it has been widely reported that a significant loss in strength occurs when concrete is heated above $300^{\circ} \mathrm{C}$ and that normally this coincides with a concrete colour change of red or pink [13] as in Fig. 5 (b). RGB Image analysis of concrete specimens captured by a flatbed scanner was done on small cropped image sections of size $7 \times 7 \mathrm{~cm}$ in order to reduce computational intensity and Fig. 6 shows the results.

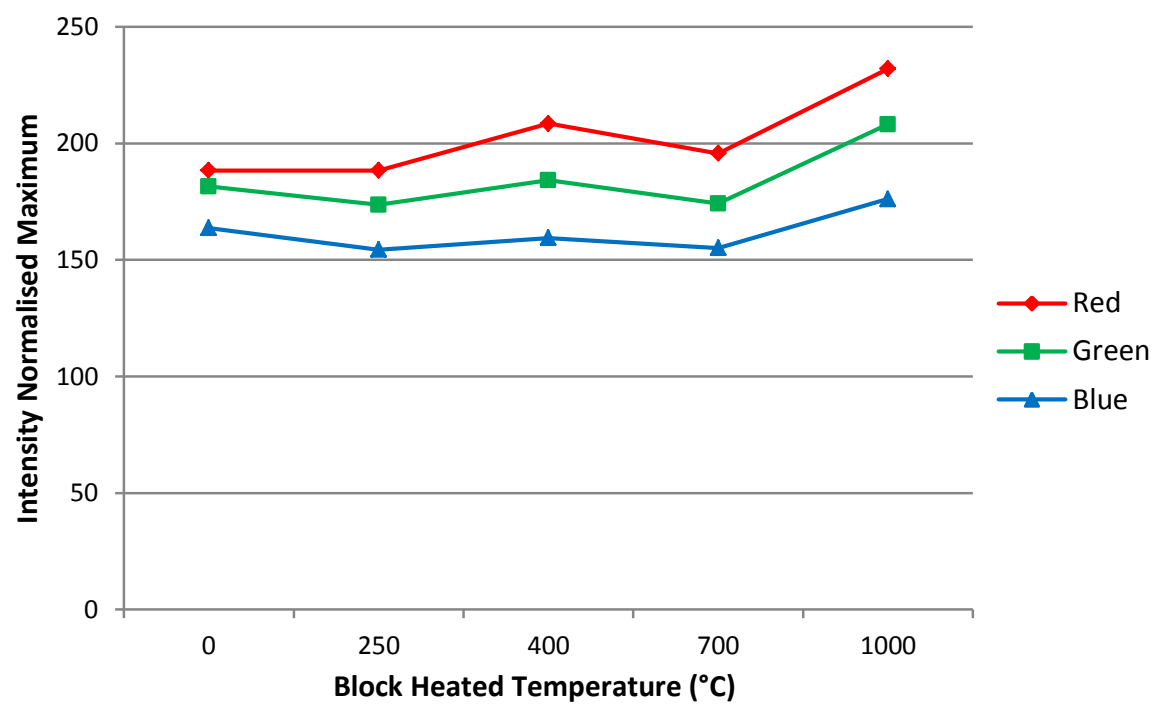

Fig. 6: Flatbed Scanner RGB Grayscales of intensity of maximum normalised values against the temperature to which each block was heated to. 
Fig. 6 above shows the intensities of the three primary colours i.e. red, green and blue colours at different designated temperatures for concrete specimens. It can be observed that the red and green colours start at almost around the same point. Throughout the temperature range investigated the red and green colour intensities were higher than the blue colour. However, the blue colour like the green and red colours, showed a significant raise in intensity for the concrete specimen heated to $1000^{\circ} \mathrm{C}$. The variations in intensity for the RGB channels in Fig. 6 were explained by the colour changes of the heated concrete (Fig. 5).

\subsection{Relation of Incidence Angle and Distance}

The measurement of the incidence angles for the blocks in the experiments (see measurement setup in section 2.3) varied with distance. As the scanning distance increased, the incidence angle decreased and both scanners used showed the same trend as shown in Fig. 7 and 8 below:

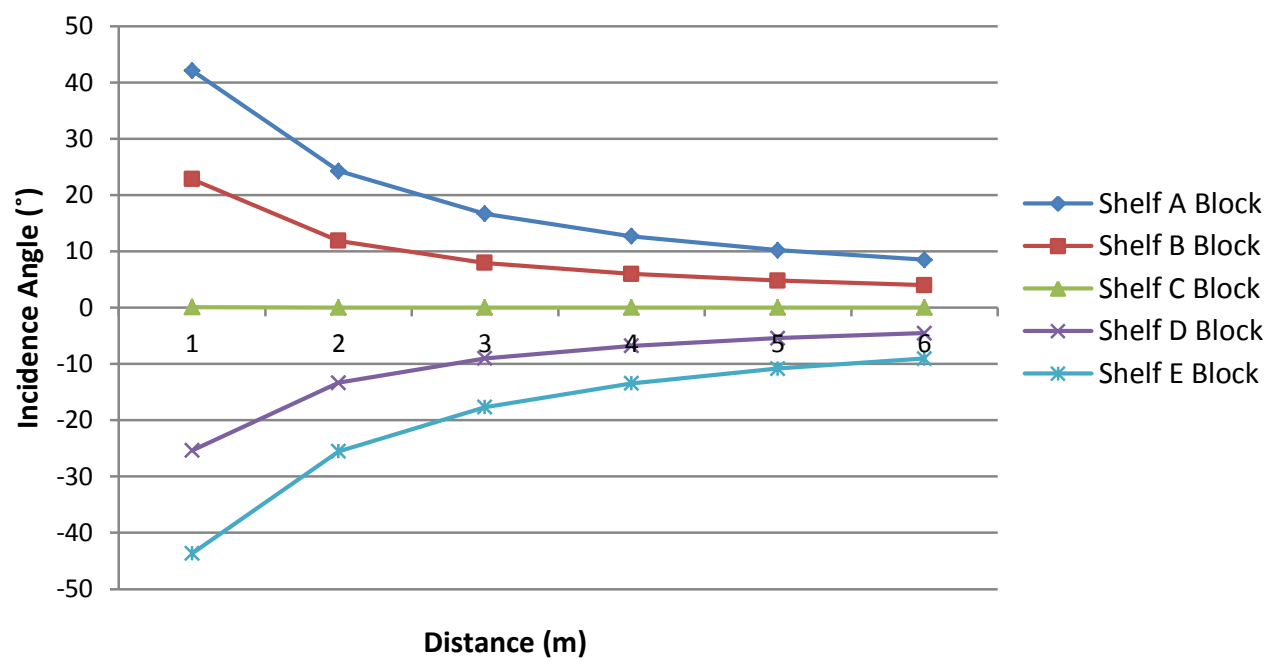

Fig. 7: Incidence Angle against Distance - HDS7000 Scanner

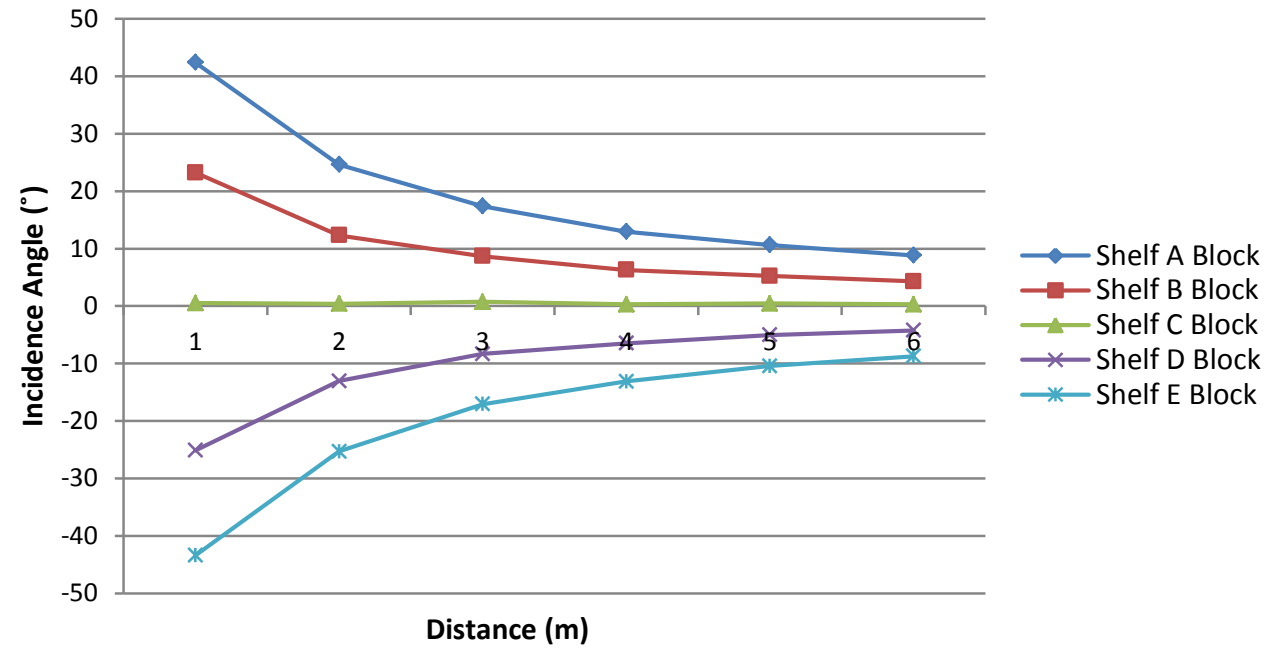

Fig. 8: Incidence Angle against Distance - FARO Scanner

In line with the above findings, Krooks et al. [26] also investigated the relation between incidence angle and distance (range) and it has been reported that in several fieldwork applications of static TLS where a survey is conducted with the scanner mounted on the tripod, changes in the angle of incidence occur as the measurement range increases. 


\subsection{Effects of Incidence Angle and Distance on Intensity}

In theory, the closer the laser beam incidence angle is to $0^{\circ}$ the more the returned intensity. It has been reported that higher incidence angles of for instance $20^{\circ}$ and more lead to diminished returned intensity [26]. The results presented below are for blocks that were scanned at incidence angles less than $12^{\circ}$ and with the scanning distance held fixed. Fig. 9 and 10 show the relationship between intensity and incidence angle and it can be seen that the effect of the incidence angle on the intensity is insignificant as the graphs for all the blocks tend to straighten across the whole range of the incidence angles.

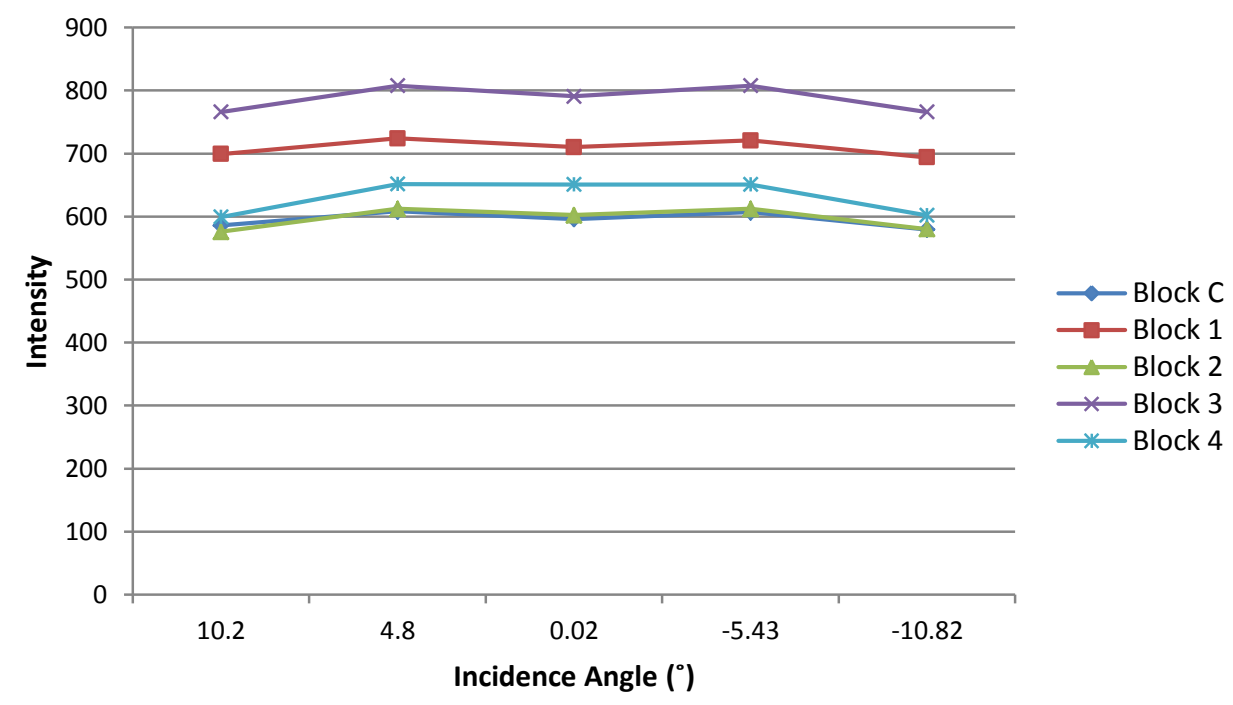

Fig. 9: Intensity against Incidence Angle at 5m - HDS7000

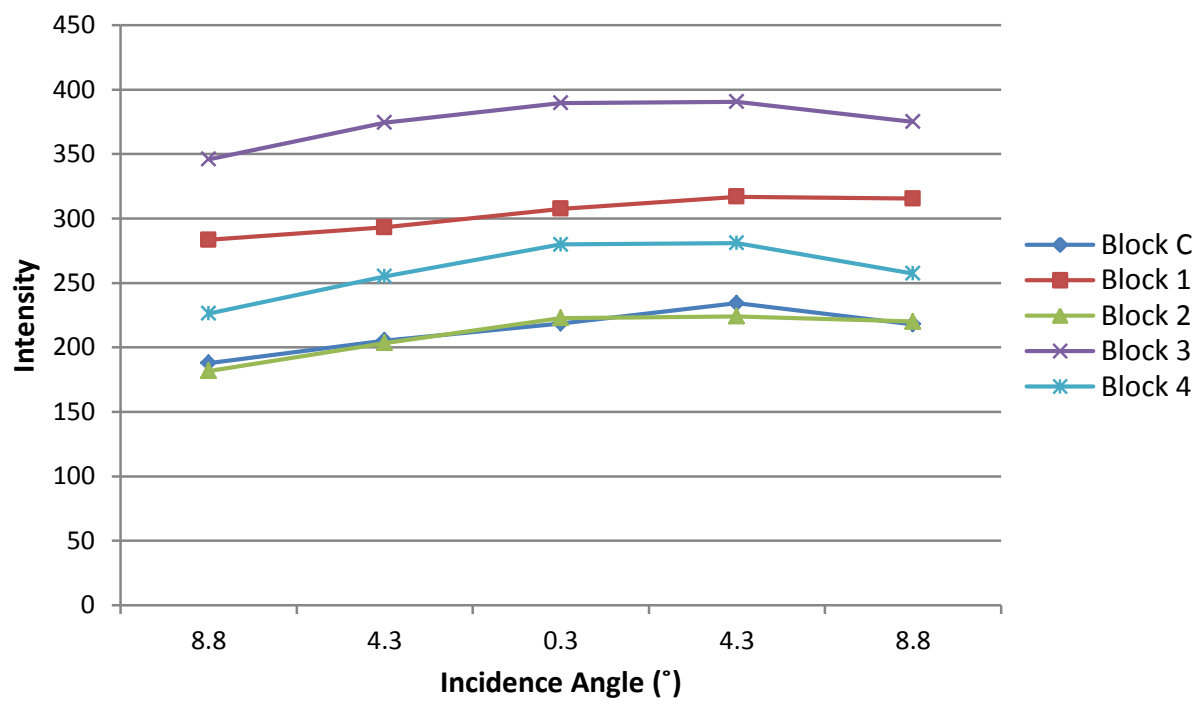

Fig. 10: Intensity against Incidence Angle at 6m - FARO

In order to assess the effects of the distance on the intensity for the HDS7000 and FARO scanner data, the scanning incidence angle for the blocks was kept constant at $0^{\circ}$ and only the distance was varied. The intensity-distance relationships for the concrete intensity data for all the blocks as scanned with the HDS7000 scanner are as shown in Fig. 11. The distance effects can be clearly observed for the uncorrected intensity as the expected theoretical trend where intensity return decreases with an increase in distance does not hold. The possible explanation for this is attributed to the instrumental effects of the scanner such as near distance reducers and logarithmic amplifiers which influence the laser measurements as documented in literature for various scanners [33]. 




Fig. 11: Intensity against Distance at $0^{\circ}$ Incidence Angle - HDS7000

The intensity-distance relationship for the FARO scanner data (Fig. 12) followed the theoretical trend of intensity decreasing with an increase in scanning distance. However, a slight amplification of the intensity was observed after $5 \mathrm{~m}$.

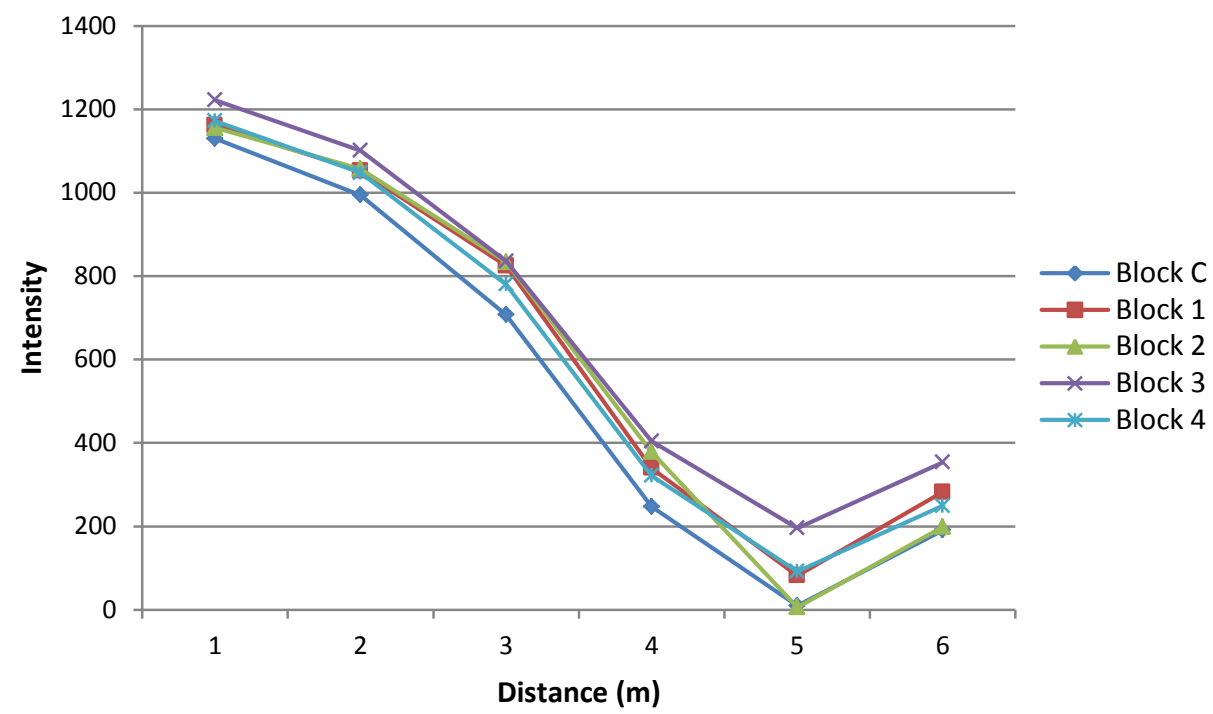

Fig. 12: Intensity against Distance at $0^{\circ}$ Incidence Angle - FARO

The HDS7000 concrete intensity data was corrected for near distance effects by applying the correction method proposed in Fang et al. [31]. The intensity-distance relationship results after the correction was applied are as presented in Fig. 13 and it can be clearly seen that the correction is valid for distances greater than $1 \mathrm{~m}$ as the rest of the scanning distances investigated follow the theoretical trend where a decreasing course for the intensity is observed over the whole range of scanning distances as the distance increases. Several researchers such as Kaasalainen et al. [27] have reported that scanning measurements taken at short ranges of $1 \mathrm{~m}$ for instance have their intensities reduced in order to avoid overexposure of the scanner's photo-detector. In a similar vein Antilla et al. [18] used the HDS6000 scanner and reported that for the first $5 \mathrm{~m}$ distances, the intensity is reduced so as to keep the level of the intensity within the realm of the sensor's dynamic range and from $5 \mathrm{~m}$ and above, the intensity roughly follows the range squared inverse as described in the radar range equation. 


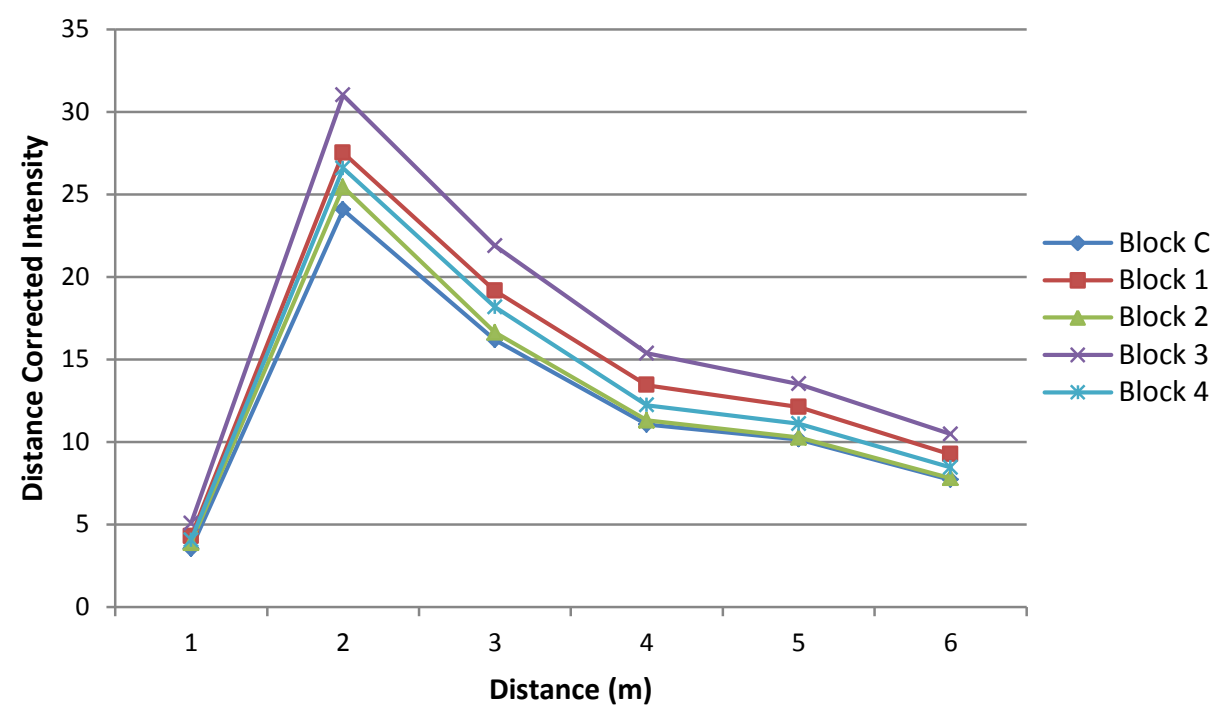

Fig. 13: Intensity against Distance at $0^{\circ}$ Incidence Angle - HDS7000

\subsection{Intensity and Block Heated Temperature}

An analysis of the intensity recorded by the laser scanners for the heated blocks was carried out with the aim of studying the relationship between intensity and the temperature to which the blocks were heated. The data analysed and the results presented below are for blocks that were scanned at incidence angles less than $12^{\circ}$ and with the scanning distance held fixed. Results of the relationship between intensity and the temperature to which the blocks were heated are as shown in Fig. 14 for the HDS7000 data and Fig. 15 for the FARO data. It can be observed that the intensity grows with the exposure temperature for the blocks. Several scanning distances were tested in an effort to find distances at which the relationship fits reasonably well and the result was such that the graphs (Fig. 14 and 15) converged to almost a straight line at a scanning distance of $5 \mathrm{~m}$ for the HDS7000 scanner and $6 \mathrm{~m}$ for the FARO scanner due to a reduction in the incidence angles $\left(<12^{\circ}\right)$ which was observed at these scanning distances. With reference to Fig. 14 and 15, the levels of fire-damaged concrete from the two scanners were assessed as shown in Table 6.



Fig. 14: Intensity against Block Heated Temperature at 5m - HDS7000 


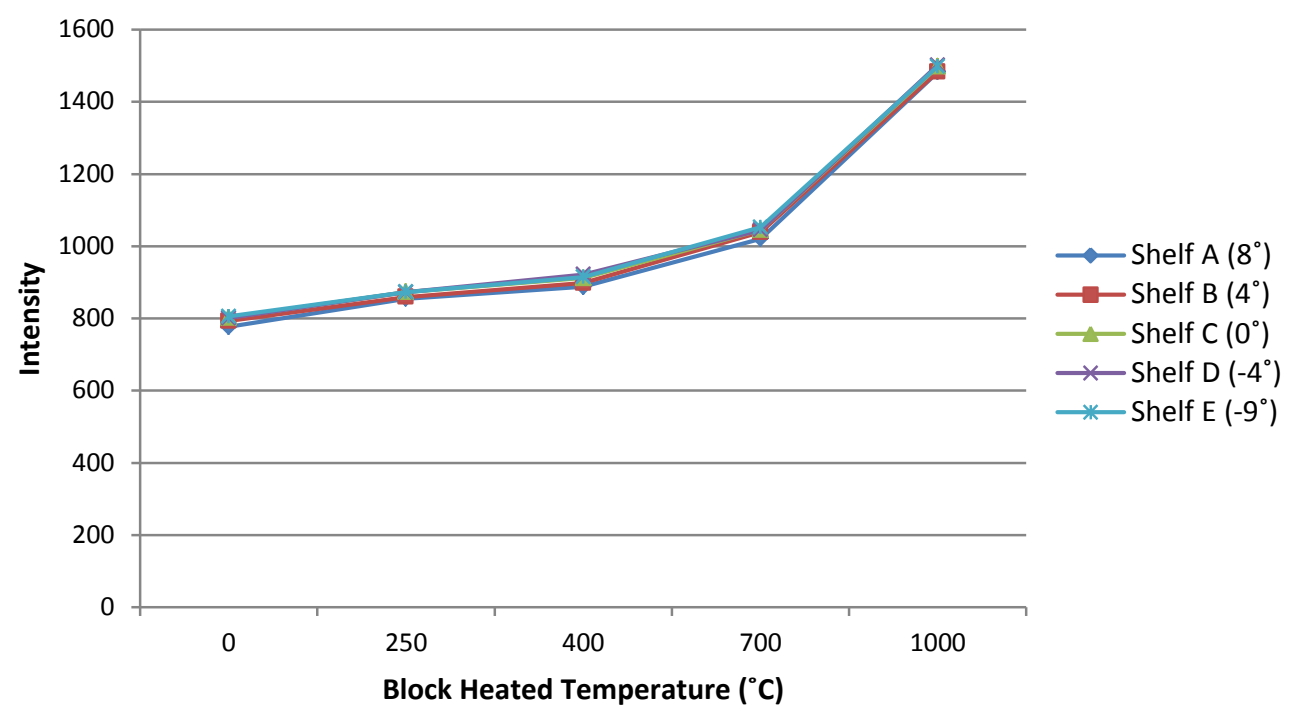

Fig. 15: Intensity against Block Heated Temperature at 6m - FARO

Table 6: Intensity Levels of Fire-Damaged Concrete

\begin{tabular}{|c|c|c|}
\hline Block Temperature & \multicolumn{2}{|c|}{ Intensity Interval } \\
\cline { 2 - 3 } & HDS7000 Scanner (5m) & FARO Scanner (6m) \\
\hline Unheated & $623-662$ & $777-806$ \\
\hline $250^{\circ} \mathrm{C}$ & $786-829$ & $855-873$ \\
\hline $400^{\circ} \mathrm{C}$ & $833-881$ & $888-922$ \\
\hline $700^{\circ} \mathrm{C}$ & $1169-1225$ & $1021-1053$ \\
\hline $1000^{\circ} \mathrm{C}$ & $2002-2019$ & $1483-1502$ \\
\hline
\end{tabular}

After correcting the HDS7000 concrete intensity data for near distance effects, the relationship between intensity and the temperature to which the blocks were heated was investigated for blocks that were scanned constantly at $0^{\circ}$ incidence angle and only varying the distances. The results of this relationship (Fig. 16) showed that the intensity grows with the exposure temperature for the blocks. The highest intensities were recorded at a distance of $2 \mathrm{~m}$ and then a decreasing course for the intensities was observed over the whole range of scanning distances as the distance increased. Lowest intensities were recorded at a distance of $1 \mathrm{~m}$ and this was attributed to be due to the instrumental effects which cause an intensity reduction at near distances to avoid sensor overexposure as mentioned above. However, even at $1 \mathrm{~m}$ distance it can be seen that the intensity increases as the exposure temperature increases for all the blocks.

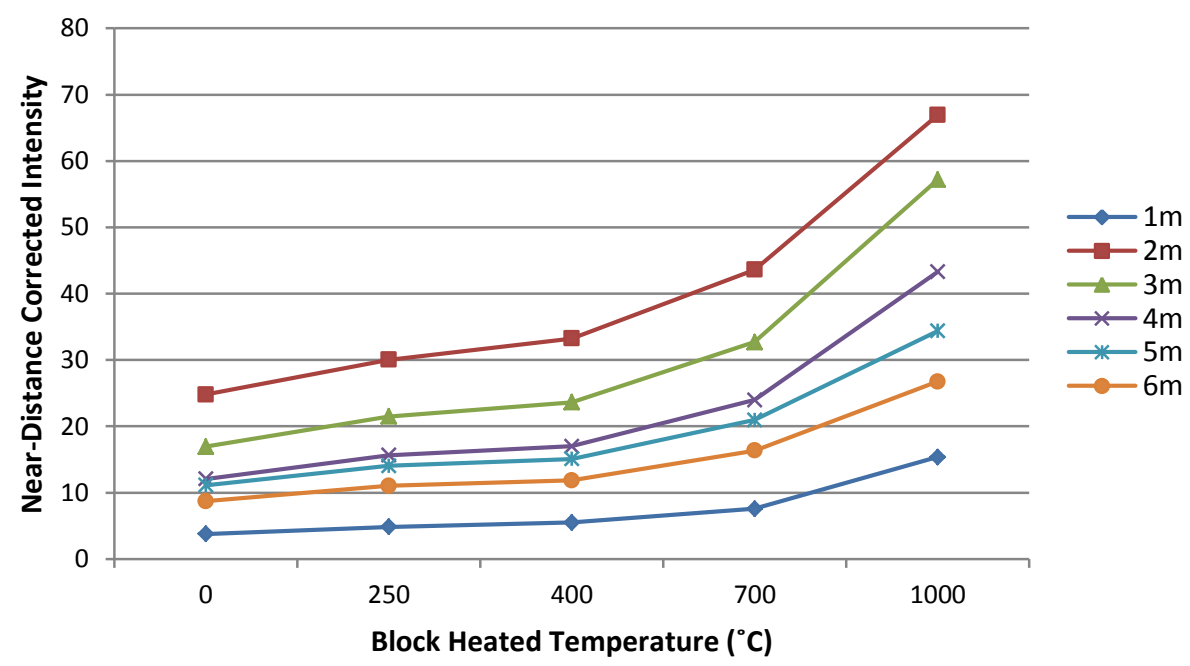

Fig. 16: Intensity against Block Heated Temperature at $0^{\circ}$ Incidence Angle 


\subsection{Comparison of Unheated and Heated Concrete}

A comparison of the intensities of the concrete blocks before and after heating was investigated aimed at assessing if there were any differences and recognisable patterns rather trends that could be drawn in relation to exposure temperature that each block was heated to. The results of the comparison are shown in Fig. 17 for the HDS7000 scanner data and in Fig. 18 for the FARO scanner data. The results presented are for scans that were taken at a scanning distance of $3 \mathrm{~m}$ and at various incidence angles. It can clearly be seen from both Fig. 17 and 18 that the intensity values of the blocks increase after heating. Furthermore, an upward trajectory trend can be seen where the intensities of the blocks increase in relation to the increase in exposure temperatures of the blocks i.e. block $1\left(250^{\circ} \mathrm{C}\right)$, block $2\left(400^{\circ} \mathrm{C}\right)$, block $3\left(700^{\circ} \mathrm{C}\right)$ and block 4 $\left(1000^{\circ} \mathrm{C}\right)$. The observations held true for all the incidence angles and other scanning distances investigated though an optimised scanning geometry produced better results.

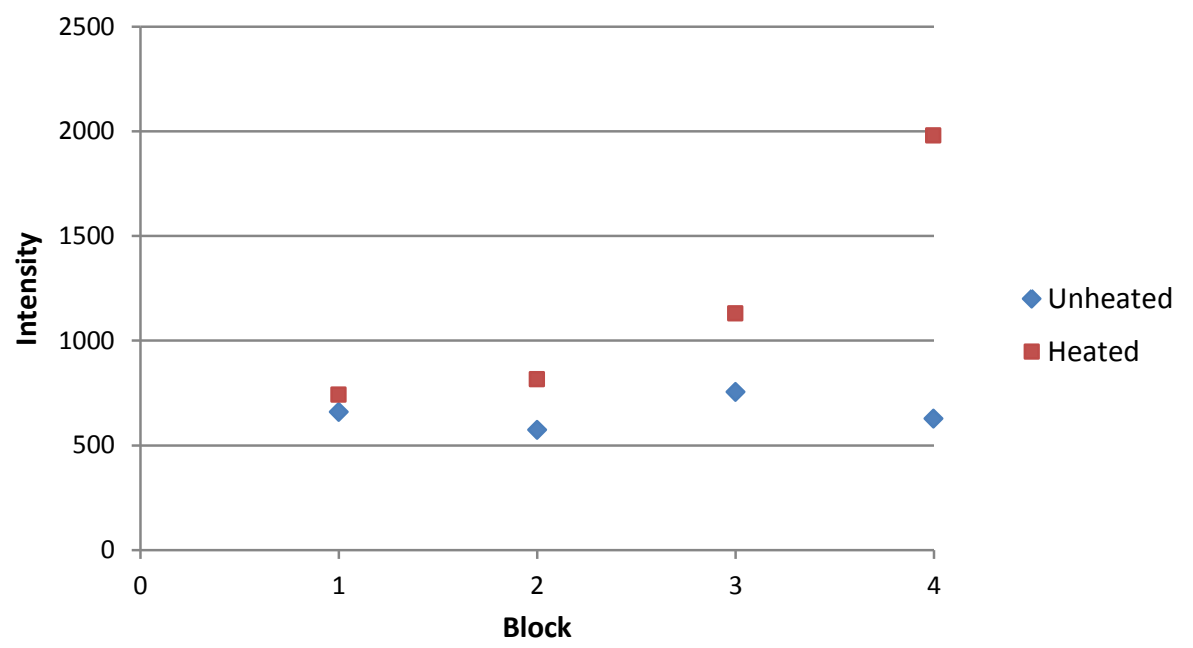

Fig. 17: Comparison of Unheated and Heated Concrete at $0^{\circ}$ Incidence Angle - HDS7000

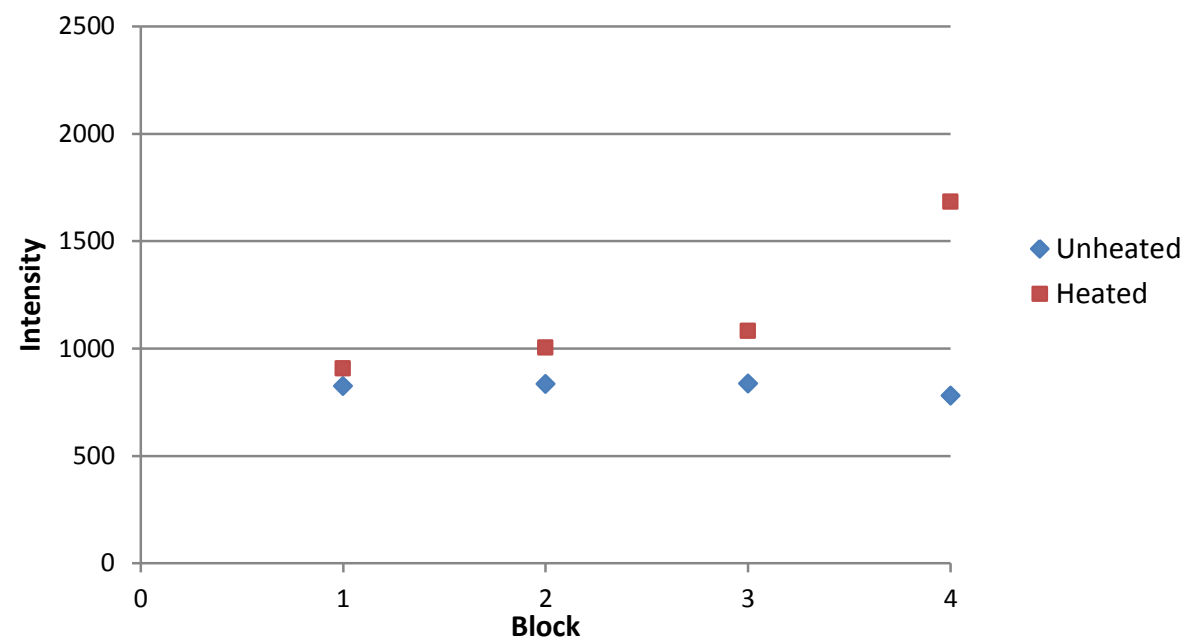

Fig. 18: Comparison of Unheated and Heated Concrete at $0^{\circ}$ Incidence Angle - FARO

\section{Discussion}

The measurement of the incidence angles from the various distances was found to be wavelength independent for both scanners (HDS7000 and FARO) used and this is a promising factor in terms of developing standardised analysis tools for the incidence angle although several scanners need to be tested. The effects of the distance and incidence angle on the intensity of concrete specimens were found to be independent and this made it possible to properly relate each one of them to the intensity and draw meaningful relationships. Furthermore, this finding made it possible to correct the concrete intensity acquired using the 
HDS7000 scanner for near distance effects. In a similar vein, Krooks et al. [26] also reported that distance and incidence angle effects on the intensity do not mix, implying that a correction of both effects is possible by using different models that are independent of the measurement.

The relationship between intensity and the blocks which were heated to various temperatures was investigated by scanning the blocks at the respective distances and varying the incidence angles. The results of this relationship from both scanners showed that the intensity grows with the exposure temperature for the blocks. The results of the near distance corrected HDS7000 concrete intensity data also showed that the intensity grows with the exposure temperature for the blocks when the scanning incidence angle is fixed and the distances are varied. The achieved positive results relating intensity to exposure temperature of concrete demonstrate that laser scanning can be applied to assess levels of fire-damaged concrete and provide an understanding of the condition of concrete in relation to the strength changes of concrete when it is heated to elevated temperatures. It is worth stating that the influence of colour change of the heated concrete specimens on the intensity return did play a role to a certain extent as colour change is as a result of concrete composition and heating the concrete to elevated temperatures. Laser scanner intensity gave better results compared to intensity of RGB channels in terms of relating intensity to concrete exposure temperature. However, the results of RBG image analysis have shown that RGB can indeed be useful in roughly assessing the maximum temperature attained in fire-damaged concrete. From a colourimetry point of view laser scanners have an advantage as most of them have an external or internal camera which can be used to capture concrete images if good resolution can be achieved.

A comparison of heated and unheated concrete based on the laser scanner intensity to assess if there was a difference between heated and unheated concrete proved successful. Results from the two scanners clearly showed that there is a remarkable difference in the intensity values of heated and unheated concrete and it was observed that the intensity values increased with an increase in exposure temperature. The results of this comparative analysis are valuable in that they have shown that it is possible to use laser scanning to identify differences in the state of concrete before and after heating as a change detection technique.

\section{Conclusion and Recommendations}

A method that employs TLS for detection of fire-damaged concrete was investigated. The concrete specimens were exposed to various temperatures since the core issue to consider in an investigative experiment on the effects of fire-damaged concrete is the temperature attained during the heating period. The influences of scanning geometry on the laser returned intensity was examined. The following conclusions were drawn from the study:

i. There is a positive correlation between the laser intensity and the various temperatures to which the blocks were heated.

ii. The laser intensity recorded for heated concrete is higher than that of unheated concrete, and this difference is greater when the concrete exposure temperature is higher. This makes it possible to detect heated and unheated concrete.

iii. Among other factors such as scanning geometry and instrumental effects, the concrete composition and the effects of heating concrete to elevated temperatures influence the resultant concrete physical features, colour change and the eventual laser returned intensity.

iv. Although the laser scanners used in this study have different wavelengths, the results obtained in both cases clearly demonstrate the feasibility of using TLS to detect firedamaged concrete as a new technique.

v. The study has also shown that indeed RGB data improve the visual identification of features and provide a rough idea of the concrete condition after a fire. However, instead of using a flatbed scanner, a laser scanner internal or external camera can be used to capture concrete images. The challenge with the laser scanner cameras as used 
in this study is that they are of poor resolution for image analysis purposes. If the design of the laser scanner cameras can be of good resolution, then TLS can be applied as a standalone technique capable of detecting fire-damaged concrete from both analysis of intensity return and analysis of images captured by the scanner camera.

vi. The proposed detection technique for fire-damaged concrete can work on both the TLS and Airborne Laser Scanning (ALS) platforms as the scanning principle is generally the same. Actually it would be very ideal for ALS in cases of detecting high-rise firedamaged concrete structures and there are proven intensity correction algorithms for ALS intensity data.

A brief account on the areas planned for further research concerning the use of laser scanning to detect fire-damaged concrete is provided below:

i. Replicate the same proposed detection technique but outdoor and at baselines longer than the ones tested in this study and use a spectrometer for extracting spectral characteristics of the concrete specimens so as to check the results at the wavelengths ranges of the laser scanners used.

ii. Experiment the proposed detection technique with different types of concrete and with different physical characteristics for instance smooth, rough or painted concrete and also integrate methods of quantifying the colour development of heated concrete.

\section{Acknowledgements}

The Authors express their gratitude to the University of Nottingham Ningbo China for the scholarship for the $\mathrm{PhD}$ student and the research facilities which made this study to be undertaken. Many thanks also to Huib de Ligt, technical staff in the civil engineering department for the support regarding the work.

\section{References}

1. Junaid, M. T., Khennane, A., Kayali, O., Sadaoui, A., Picard, D. and Fafard, M. (2014) Aspects of the deformation behaviour of alkali activated fly ash concrete at elevated temperatures. Journal of Concrete and Cement Research 60:24-29.

2. Maia, L. and Figueiras, J. (2012) Early-age creep deformation of a high strength compacting concrete. Journal of Construction and Building Materials 34:602-610.

3. Chan, Y. N., Peng, G. F. and Anson, M. (1999) Residual strength and pore structure of highstrength concrete and normal strength concrete after exposure to high temperatures. Cement and Concrete Composites 21(1):23-27.

4. Ergün, A., Gökhan, K., Serhat, B. M. and Mansour, M. (2013) The effect of cement dosage on mechanical properties of concrete exposed to high temperatures. Fire Safety Journal 55:160167.

5. Ingham, J. (2009) Forensic engineering of fire-damaged structures. Proceedings of Institution of Civil Engineers 162(5):12-17.

6. Yang, H., Lin, Y., Hsiao, C and Liu, J. (2009) Evaluating residual compressive strength of concrete at elevated temperatures using ultrasonic pulse velocity. Fire Safety Journal 44(1):121130.

7. Felicetti, R. (2013) Assessment methods of fire damages in concrete tunnel linings. Fire Technology 49(2):509-529.

8. Gosain, N. K., Drexler, R. F. and Choudhuri, D. (2008) Evaluation and repair of fire-damaged buildings, structural forensics - investigating structures and their components (on-line) http://www.structuremag.org/wp-content/uploads/2014/08/C-STRForensics-Fire-GosainSept081.pdf, accessed on 12.05.2014.

9. Short, N. R., Purkiss, J. A and Guise, S. E. (2001) Assessment of fire damaged concrete using colour image analysis. Construction and Building Materials 15(1):9-15.

10. Cioni, P., Croce, P. and Salvatore, W. (2001) Assessing fire damage to reinforced-concrete elements. Fire Safety Journal 36:181 -199. 
11. Luo, X., Sun, W. and Chan, S. Y. N. (2000) Effect of heating and cooling regimes on residual strength and microstructure of normal strength and high-performance concrete. Cement and Concrete Research 30(3):379-383.

12. Georgali, B. and Tsakiridis, P. E. (2005) Microstructure of fire-damaged concrete: a case study. Cement and Concrete Composites 27(20):255-259.

13. Chew, M. Y. L. (1993) The assessment of fire damaged concrete. Building and Environment 28(1):97-102.

14. Annerel, E. and Taerwe, L. (2011) Methods to quantify the colour development of concrete exposed to fire. Construction and Building Materials 25(10):3989-3997.

15. Hager, I. (2013) Colour change in heated concrete. Fire Technology 50:945-958.

16. Colombo, M. and Felicetti, R. (2007) New NDT techniques for the assessment of fire-damaged concrete structures. Fire Safety Journal 42(6-7):461-472.

17. Höfle, B. and Pfeifer N. (2007) Correction of laser scanning intensity data: data and modeldriven approaches. ISPRS Journal of Photogrammetry and Remote Sensing 62(6):415-433.

18. Anttila, K., Kaasalainen, S., Krooks, A., Kaartinen, H., Kukko, A., Manninen, T., Lahtinen, P. and Siljamo, N. (2011) Radiometric calibration of TLS intensity: application to snow cover change detection. International Archives of the Photogrammetry, Remote Sensing and Spatial Information Sciences 38(5):175-179.

19. Penasa, L., Franceschi, M., Preto, N., Teza, G. and Polito, V. (2014) Integration of intensity textures and local geometry descriptors from terrestrial laser scanning to map chert in outcrops. ISPRS Journal of Photogrammetry and Remote Sensing 93:88-97.

20. Teza, G., Galgaro, A. and Moro, F. (2009) Contactless recognition of concrete surface damage from laser scanning and curvature computation. NDT \& E International 42(4):240-249.

21. Lichti, D. D and Harvey, B. (2002) The effects of reflecting surface material properties on timeof-flight laser scanner measurements. Proceedings of Joint International Symposium on Geospatial Theory, Processing and Applications, Ottawa, Canada.

22. Soudarissanane, S., Lindenbergh, R., Menenti, M. and Teunissen P. (2011) Scanning geometry: influencing factor on the quality of terrestrial laser scanning points. ISPRS Journal of Photogrammetry and Remote Sensing 66(4):389-399.

23. Hancock, C. M., Roberts, G. W., Bisby, L., Cullen, M. and Arbuckle, J. (2012) Detecting fire damaged concrete using laser scanning. FIG Working Week 2012, Rome, Italy, May 6-10.

24. Leica Geosystems (2012) HDS7000 user manual (on-line) http://hds.leica-geosystems.com, accessed on $14^{\text {th }}$ July 2014.

25. FARO Technologies (2011) FARO laser scanner focus ${ }^{3 \mathrm{~d}}$ user manual.

26. Krooks, A., Kaasalainen S., Hakala T. and Nevalainen, O. (2013) Correction of intensity incidence angle effect in terrestrial laser scanning. ISPRS Annals of the Photogrammetry, Remote Sensing and Spatial Information Sciences 2(5/W2):145-150.

27. Kaasalainen, S., Jaakkola, A., Kaasalainen, M., Krooks, A. and Kukko, A. (2011) Analysis of incidence angle and distance effects on terrestrial laser scanner intensity: search for correction methods. Remote Sensing 3:2207-2221.

28. Biolzi, L., Cattaneo, S. and Rosati, G. (2008) Evaluating residual properties of thermally damaged concrete. Cement and Concrete Composites 30(10):907-916.

29. Soudarissanane, S., Lindenbergh, R., Menenti, M. and Teunissen, P. (2009) Incidence angle influence on the quality of terrestrial laser scanning points. International Archives of the Photogrammetry, Remote Sensing and Spatial Information Sciences 38(3/W8):183-188.

30. Pfeifer, N. and Briese, C. (2007) Laser scanning - principles and applications, Vienna.

31. Fang, W., Huang, X., Zhang, F. and Li, D. (2015) Intensity correction of terrestrial laser scanning data by estimating laser transmission function. IEEE Transactions on Geoscience and Remote Sensing 53(2):942-951.

32. Yan, W.Y and Shaker, A. (2014) Radiometric correction and normalization of airborne LiDAR intensity data for improving land-cover classification. IEEE Transactions on Geoscience and Remote Sensing 52(12):7658-7673.

33. Balduzzi, M. A. F., Van der Zande, D., Stuckens, J., Verstraeten, W. W. and Coppin, P. (2011) the properties of terrestrial laser system intensity for measuring leaf geometries: a case study with conference pear trees (Pyrus Communis). Sensors 11:1657-1681. 